\title{
Role of Engineering Management in Reducing the Construction Projects Delay
}

\author{
Salloom A. Al-Juboori *, Mohammad K. Alazemi (M.Sc) \\ *Professor in Mechanical and systems engineering (B.Sc Mech., PhD, M.Sc Leeds University, and \\ U.K)/ Engineering Faculty /Mutah University / Jordan
}

\begin{abstract}
The problem of projects delay is a fact that happens mostly in constructions industry in many countries. Delay is always measured as expensive to all parties concerned in the projects and very often it will result in clash, claims, total desertion and much difficult for the feasibility and it slows the growth of constructions sector. For analyzing the causes of delay, a questionnaire on construction project's time performance was designed. Delay means the loss of money for extra spending on equipment and materials and hiring the labors and loss of time. So, the main objective of this study is to identify the factors of delay and their effects on the success and completion of projects. The methodology was by designing a professional questionnaire survey distributed to a sample of the population who are working in the constructions sector in Kuwait-as a case study. The answers of the respondents were analyzed using SPSS package. The results of analysis have shown that there are many reasons causing delays, but the most effective are: the projects bids, where respondents have agreed on this by $93.3 \%$, the lack of coordination at work between the parties was 90.4 $\%$, due to delayed payment to contractors was 90.3, while the lack of follow-up to the decisions of the senior management was $81.8 \%$.This is the lowest percentage of the fourteen causes of delay answered by respondents on the high impact questions. The major effects of delay are cost impact; reduced labor productivity failure to provide affords the workers. Not all delays can be corrected, but few of them can be overcome by improving management responsibilities. The respondents who have answered by agree and strongly agree to the selected questions represent between $78.9 \%$ and $93.3 \%$ of the present study sample which is a very significant indication of diagnostic the preseason's of construction projects delay in present work case-study
\end{abstract}

Keywords: Projects, Delay, Construction, conflict, Management, reasons and cost.

\section{INTRODUCTION}

Project delays are a common problem internationally in the construction industry in modern times. Investigating the reasons for delay has become an important contribution to improved construction industry performance. Over seventy percent of projects initiated in some countries are likely to escalate in time with a magnitude of over fifty percent. (Seboru, April 8, 2015). However Aedwin and Shibi, 2015 have shown that the time, quality and economy constitute the three main factors in a construction project, of which time plays a significant role inconstruction in additional delay in any task or operation is a time over run which influences the completion of the work. The common problems in civil engineering projects all around the world are mainly due to delay in construction. These problems occur frequently during project duration leading to disputes and litigation more ever, Towhid and Ismal, 2012 said that the delays are one of the biggest problems in construction projects in developing countries, as cause a negative effects on the projects. Delays can be minimized only when their causes are identified. The aim of this work is to identify the main causes and effects of delay in Kuwait construction projects. However, Frank and etal, 2010 in their study investigated the causes of delay of building construction projects in Ghana, he determined, 2015 the important cuses to the key project participants; clients, consultants, and contractors. Whatever Omayma and Mohammed said the financial crisis in late 2008 arrested economic development in the construction sector in the Middle East, with the result that investors' confidence in the sector is severely depressed. Delays constitute one of the highest impediments to project success. In this respect, the traditional management is no longer sufficient for construction project success. The top three most important factors that contributed to the causes of delays were late in revising and approving design documents, delays in sub-contractors work, and poor communication and coordination change orders by owner 
during construction. Contractor related delays was ranked the most significant groups that cause delays, followed by client- related delays, and consultant-related delays. (Prakash and Culas, June, 2014). It is widely accepted that a project is successful when it is finished on time but unfortunately, due to many reasons, in many countries a large number of construction projects fail to meet their original contact time. Construction delays are the most serious problems which send bad signals to foreign investors there by slowing down the national development. A comprehensive survey; therefore, on time performance of various construction projects was carried out to identify the critical factors that cause construction delays in some countries (Gidado and Ghulam, 10-11th September, 2012.)

The characteristic of construction industry is uncertainties, unpredictability and susceptible to understandings leading to delays. Delays in construction can affect the overall project participants adversely. It is the common interest of all parties to avoid the delay as much as possible at the first place and to minimize then even if the delays arise (Ayudhya, Nov. 2011). The problem of delays in construction project is a global phenomenon and there is no exception in Kuwait stat have many construction projects and the large number are Daley that mean we have biggest problem of the delay projects and should be to investigate this problem by research (Haseeb,2011). According to Menesi, 2007, delays are classified into two different types to liability: as shown in figure-1, while figure-2 shows the effects of project delays

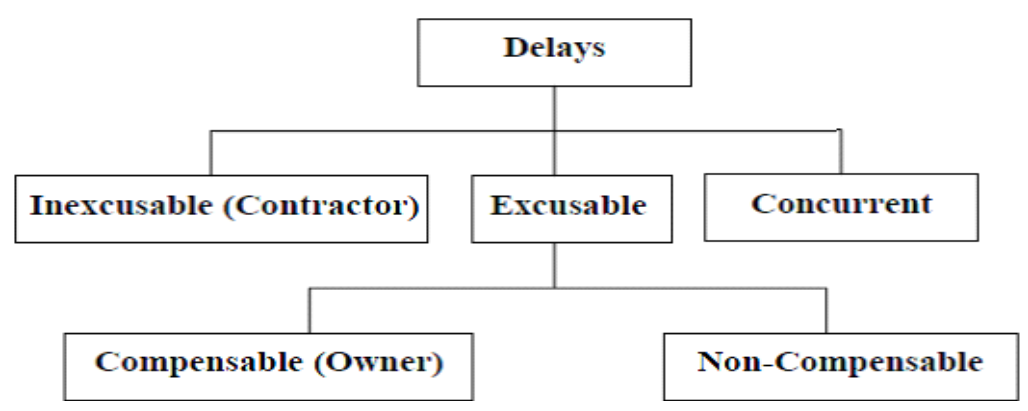

Figure1. Types of project delays MENESI (2007)

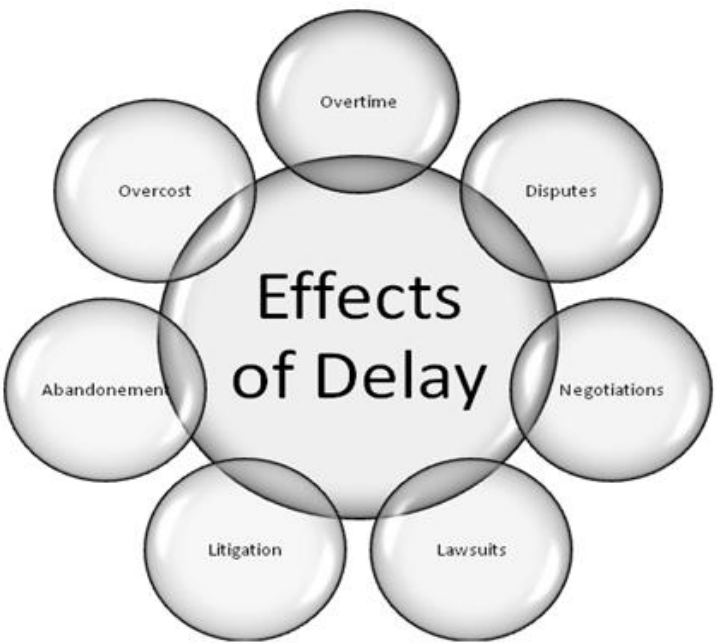

Figure2. Effects of project delays (Haseeb,2011)

\section{RESEARCH METHODOLOGY}

A special professional designed questionnaire was conducted and the answers of the respondents were analyzed by utilizing the SPSS package, reliability and validity of the questionnaire were tested.

\section{Target Group}

The target group in this work is the owners, consultants, contractor's workers and the related experience in the construction projects in Kuwaiti construction projects as a case -study. The variety of questions will be answered by each participant in the questionnaire

\section{Research Hypothesis}

The research was designed based on two types of main hypothesis, as the following: 
* Zero Hypothesis $\left(\mathrm{H}_{0}\right)$

$>$ The delay projects dos not effect on a change in essential engineering designs.

$>$ The delay projectors dos not effect on the a slow decision make

$>$ The delay projects dos not effect on the lack of experienced of the project managers

$>$ The delay projects dos not effect on the lack of experience of the site engineers

$>$ The delay projects dos not effect on the lack of the meeting with the contractors

$>$ The delay projects dos not effect on the lack of follow-up of the sponsors of the projects

* Alternative Hypothesis $\left(\mathrm{H}_{1}\right)$

$>$ The projects delay due to a change in essential engineering designs

$>$ The projects delay due to a slow decision make

$>$ The projects delay due to the lack of experienced of the project managers

$>$ The projects delay due to the lack of experience of the site engineers

$>$ The projects delay due to the lack of the meeting with the contractors

$>$ The projects delay due to the lack of follow-up of the sponsors of the projects

\section{Research variables}

Research variables are as the following:

$>$ Age of the participant.

$>$ Gender.

$>$ Job owner or consultant or contractor....etc

$>$ Number of projects which have done

$>$ Experience

$>$ The specialization of managers and engineers in construction projects positions

$>$ Are there delays in construction projects?

\section{Questionnaire scale}

The type of questionnaire is a quantity survey, where the questions are multiple choice from five scale questionnaire (strongly agree, agree, uncertain, disagree and strongly disagree), these choices will determine whether the facing statement is true or not and the degree of its truth or untruth.

\section{ANALYSis OF THE QUESTIONNAIRE QUESTIONS}

The questionnaire will be comprised of 54 questions which were answered by research sample (questionnaires respondents). A Statistical analysis was conducted to each question as shown in tables-1 and 2 which illustrate the analysis of Q1

Table1. Q1: Are there delays in projects?

\begin{tabular}{|l|l|lr|}
\hline Number & Valid & & 0 \\
\cline { 2 - 3 } & Missing & & 04 \\
\hline Mean & 4.13 & 5.00 \\
\hline Mode & & 1.29 \\
\hline Std. Deviation
\end{tabular}

Table -1 explains that the average value of the participant answers to the question: Are there delays in projects? Which shows that the mean $=4.13$, which it can be considered a good approximation for expecting subsequent data points, also, the most frequent value of the answer or the answer that occurs most of time is the mode $=5.00$. The value of standard deviation of the respondents' answers which equals to (1.29), this provides an idea of how close the entire group of participant's answers is to the value of mean. Data groups with a small value of standard deviation have tightly grouped, accurate data. While the data groups with large value of standard deviations have data spread out over 
a wide range of values.

Table-2 shows the frequency of the respondents to each question scale. It is clear that the strongly agree to Q1 is about $54.8 \%$ and the agree answers is $27.9 \%$. While, table-3 shows the answers of the respondents to 14 selected questions which have the most impact on projects delay. It is very clear that the percentage of agree and strongly agree represents greater than $80 \%$. This indicates that without any doubt there are delays in construction projects

Table2. Frequency analysis of Q1: Are there delays in projects?

\begin{tabular}{|l|l|l|l|l|l|}
\hline & & Frequency & \multicolumn{1}{|c|}{ Percent } & \multicolumn{1}{|c|}{ Valid Percent } & Cumulative Percent \\
\hline & Strongly Disagree & 11 & 10.6 & 10.6 & 10.6 \\
\hline & Disagree & 3 & 2.9 & 2.9 & 13.5 \\
\hline & Uncertain & 4 & 3.8 & 3.8 & 17.3 \\
\hline Valid & agree & 29 & 27.9 & 27.9 & $\mathbf{4 5 . 2}$ \\
\hline & Strongly agree & $\mathbf{5 7}$ & $\mathbf{5 4 . 8}$ & $\mathbf{5 4 . 8}$ & $\mathbf{1 0 0 . 0}$ \\
\hline & Total & $\mathbf{1 0 4}$ & $\mathbf{1 0 0 . 0}$ & $\mathbf{1 0 0 . 0}$ & \\
\hline
\end{tabular}

Table3. The statistical Analysis of 14 selected Questionnaire questions

\begin{tabular}{|c|c|c|c|c|c|c|c|c|}
\hline $\begin{array}{l}\text { Questionnaire } \\
\text { Questions }\end{array}$ & 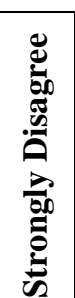 & 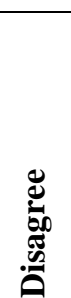 & & 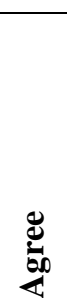 & 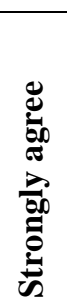 & ఏ్ & 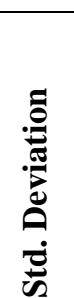 & 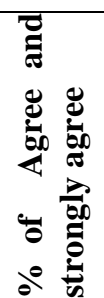 \\
\hline Q1: Are there delay projects? & 11 & 3 & 4 & 29 & 57 & 4.13 & 1.3 & 82.7 \\
\hline Q2: Do the projects bids cause the delay? & 1 & 6 & $\mathbf{0}$ & 29 & 68 & 4.14 & 0.8 & 93.3 \\
\hline Q3: Are due to delayed payment to contractors? & 1 & 5 & 4 & 30 & 64 & 4.45 & 0.9 & 90.3 \\
\hline $\begin{array}{l}\text { Q4: Is due to the change in essential engineering } \\
\text { design? }\end{array}$ & $\mathbf{1}$ & 6 & 5 & 29 & 63 & 4.41 & 0.9 & 88.5 \\
\hline $\begin{array}{l}\text { Q5: Is it due to decisions hesitation and } \\
\text { contradictory? }\end{array}$ & 1 & 6 & 4 & 29 & 64 & 4.43 & 0.9 & 89.4 \\
\hline $\begin{array}{l}\text { Q6: Is due to the lack of experience the owner of } \\
\text { the project manager and the engineers and how } \\
\text { related to the project? }\end{array}$ & $\mathbf{1}$ & 6 & 4 & 34 & 59 & 4.38 & 0.9 & 89.4 \\
\hline $\begin{array}{l}\text { Q7: Is due to the lack of coordination at work } \\
\text { between the parties? }\end{array}$ & 1 & 5 & 4 & 35 & 59 & 4.40 & 0.9 & 90.4 \\
\hline $\begin{array}{l}\text { Q8: is due to the lack of top management } \\
\text { coordination with work parties? }\end{array}$ & 1 & 8 & 4 & 35 & 56 & 4.32 & 0.9 & 87.5 \\
\hline $\begin{array}{l}\text { Q9: is due to the lack of experience of the Project } \\
\text { Manager and site engineers? }\end{array}$ & $\mathbf{1}$ & 9 & 4 & 24 & 66 & 4.39 & $\mathbf{1 . 0}$ & 86.6 \\
\hline $\begin{array}{l}\text { Q10: Is due to administration complexities and } \\
\text { administration routines? }\end{array}$ & 1 & 16 & 4 & 25 & 58 & 4.18 & 1.1 & 79.8 \\
\hline Q11: Is due to the administration decentralization? & 1 & 17 & 4 & 24 & 58 & 4.16 & 1.2 & 78.9 \\
\hline $\begin{array}{l}\text { Q12: Is due to the lack of follow-up to the decisions } \\
\text { of the senior management? }\end{array}$ & 1 & 14 & 4 & 27 & 58 & 4.22 & 1.1 & 81.8 \\
\hline $\begin{array}{l}\text { Q13: Is due to the lack of the using new } \\
\text { technology? }\end{array}$ & 1 & 15 & $\mathbf{0}$ & 26 & 62 & 4.28 & 1.1 & 84.6 \\
\hline $\begin{array}{l}\text { Q14: Is due to the pressure of higher authorities to } \\
\text { complete the projects so quickly? }\end{array}$ & $\mathbf{1}$ & 12 & $\mathbf{0}$ & 26 & 65 & 4.37 & $\mathbf{1 . 0}$ & 87.5 \\
\hline
\end{tabular}

Table-3 was illustrated in figures 4 and 5 which show the frequency respondents percentage of answering the 14 questions of LINKERT scale of agree and strongly agree, respectively. It is obvious from figure-4 that the frequency of agree the percentage is between $78.9 \%$ and $93.3 \%$. While, figure5 for strongly agree is between $50 \%$ and $68 \%$ which is less than the answers of agree percentage. Certainly both results confirm that there are delays in constructions projects.

Figure-3 shows that the frequency of respondents of Q1 LIKERT scale. The number represents who strongly agreed was 57 which is $54.8 \%$. While the number of persons who agreed was 29 which is $27.9 \%$, as well as 4 uncertain persons represents $3.8 \%$, while the number of persons who strongly 
disagreed was 11 which represents $10.6 \%$, and also the number of persons who disagreed was 3 which is $2.9 \%$. This means there are a high relation between the factor of questionnaire questions and projects delay construction project as well as the most of project manager needed to train and to manage the conflict whoever the site engineers and who related to the site work shall be to pre qualification before started the work in additional need to a criteria to select the project manager, site engineers, and even the workers

According to the following LIKERT scale figure-3 shows the respondents answers to Q1:

$1=$ strongly dies agree

$2=$ Dies agree

$3=$ Uncertain

$4=$ Agree

$5=$ strongly agree

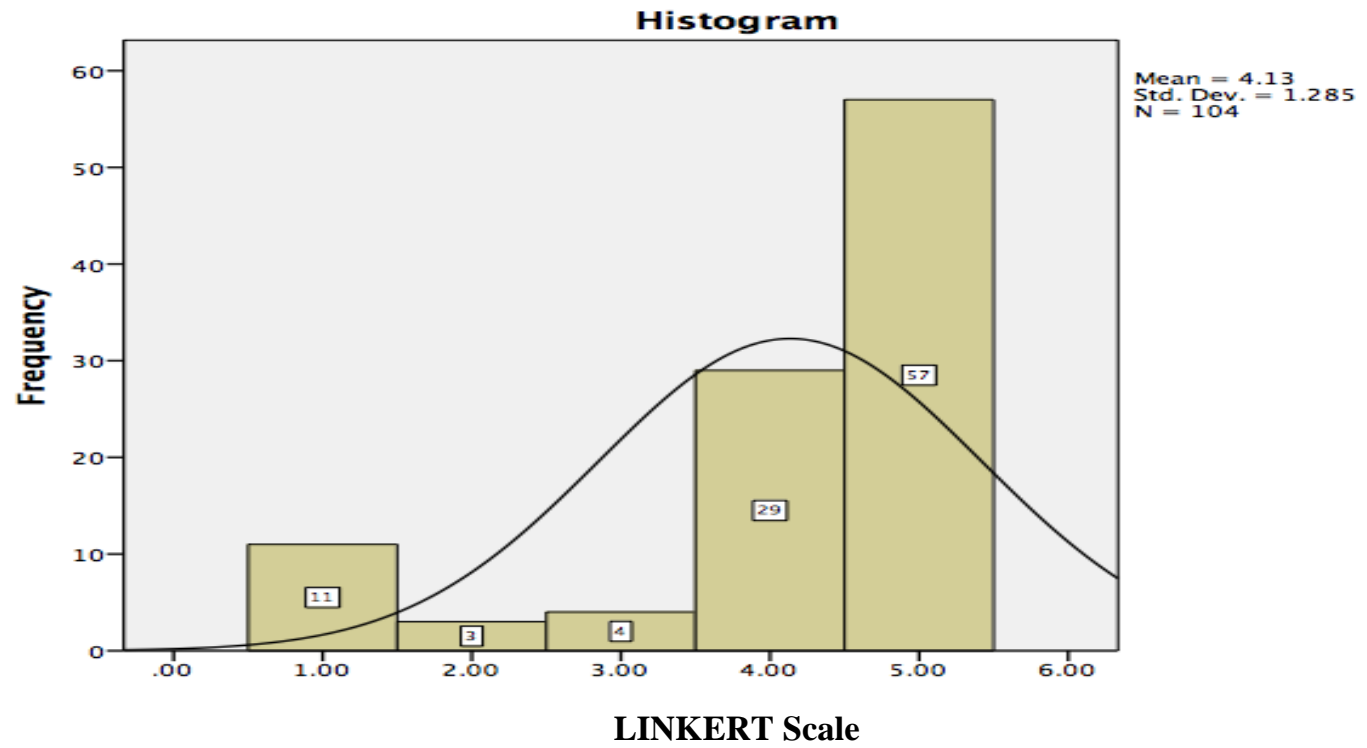

Figure3. LINKERT scale frequency of the Respondents answers to $Q 1$

The respondents of agree answers

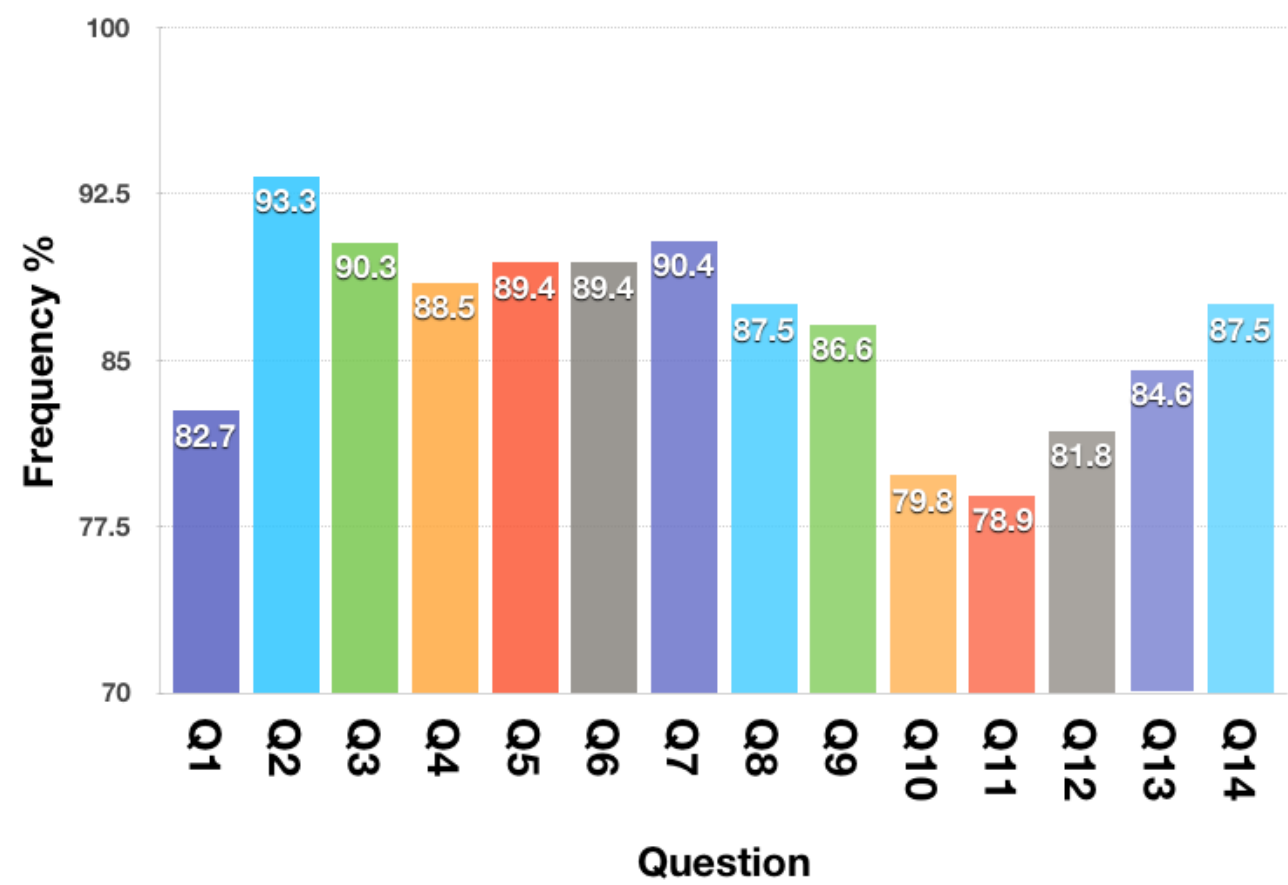

Figure4. The Frequency of Respondents of Agree Answers 


\section{Respondents of strongly agree answers}

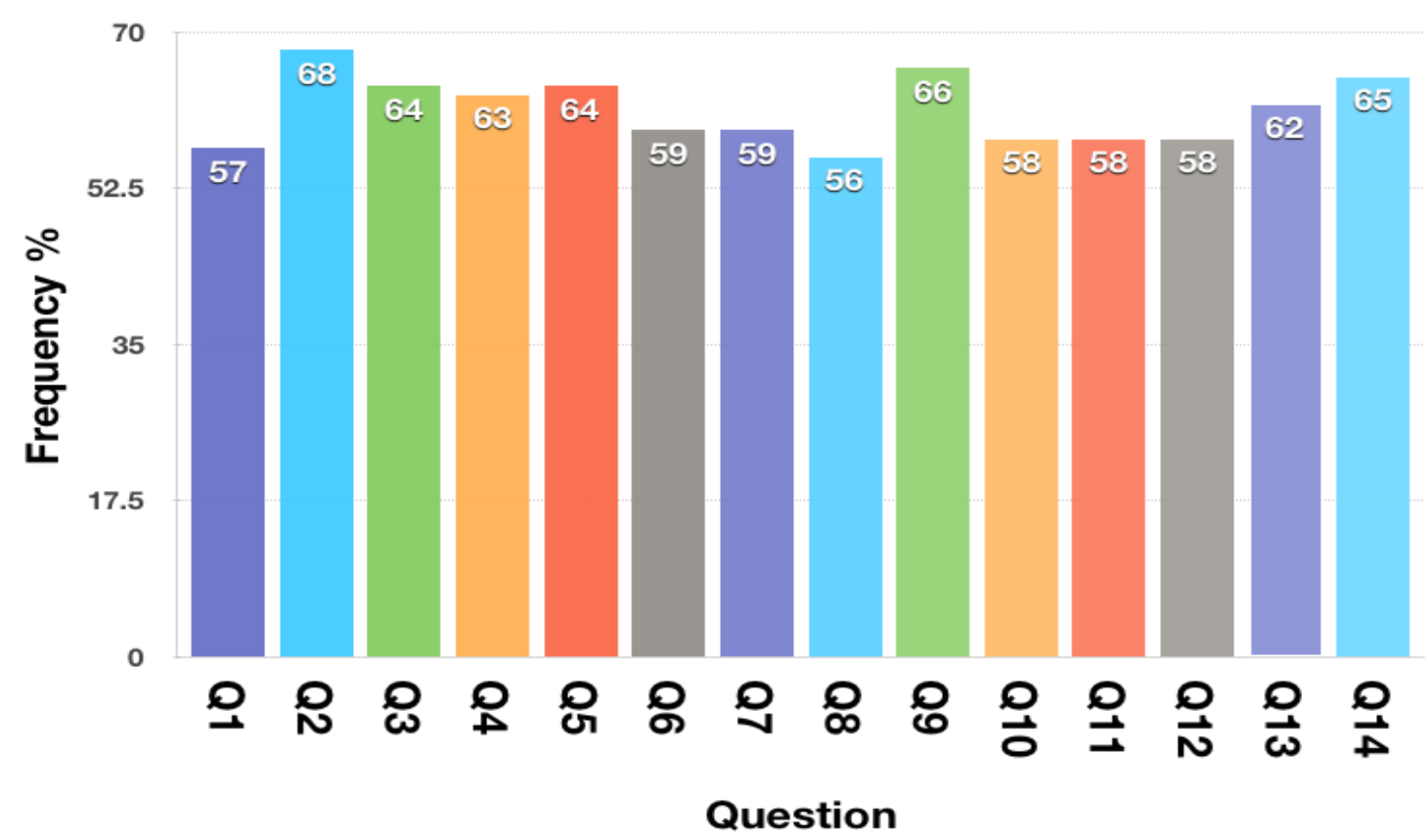

Figure5. The frequency of respondents of strongly agree answers

Figures 6-19 illustrate the statistical analysis and the frequency of the respondents answers to the samples of the questionnaire questions. Also it is clearly obvious that there are many of causes contributing in projects delay, these causes will be summarized in conclusions.

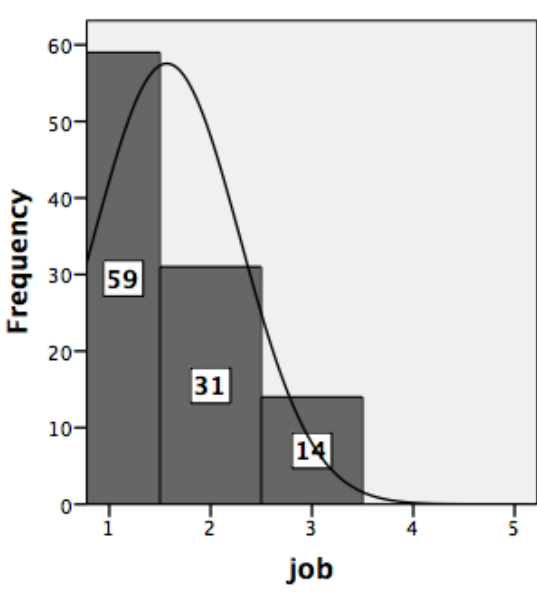

Figure6

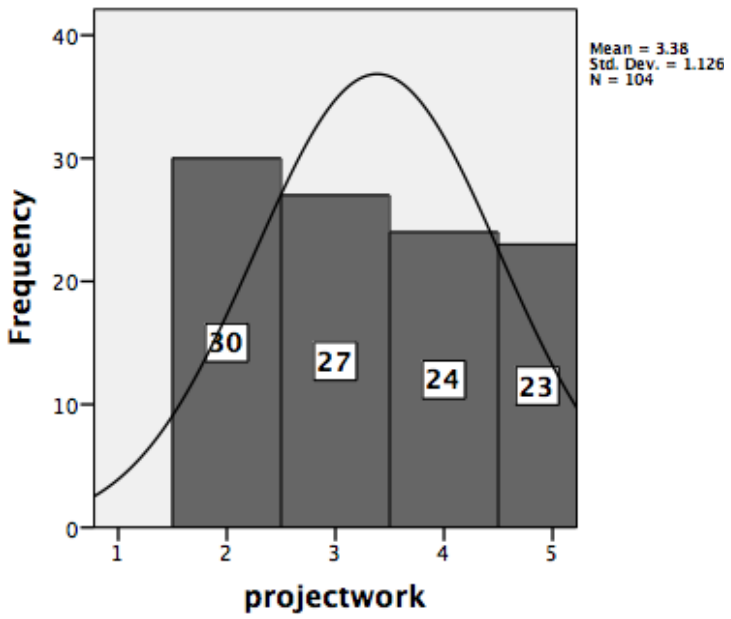

Figure8

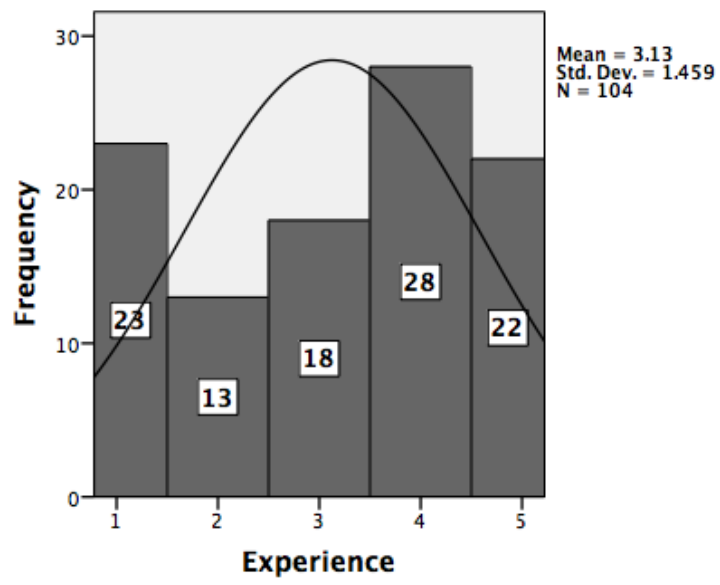

Figure7

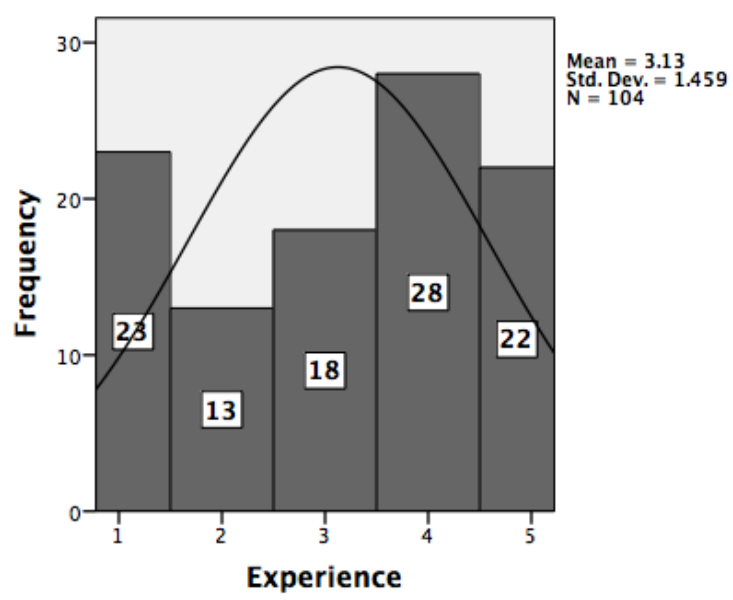

Figure9 


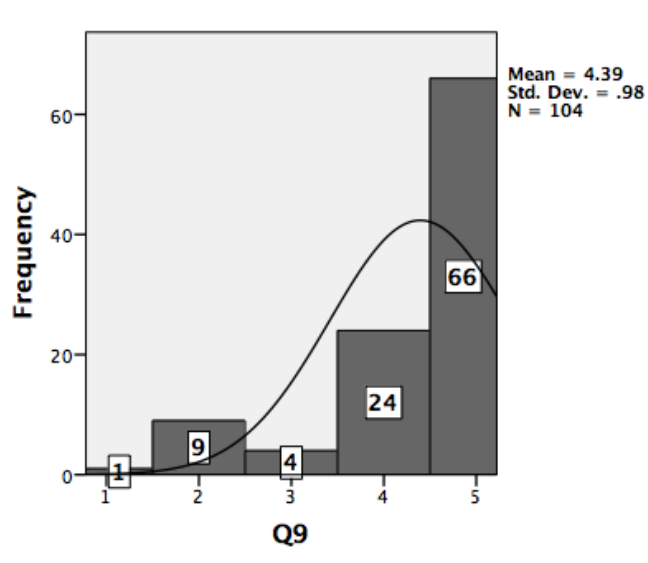

Figure10

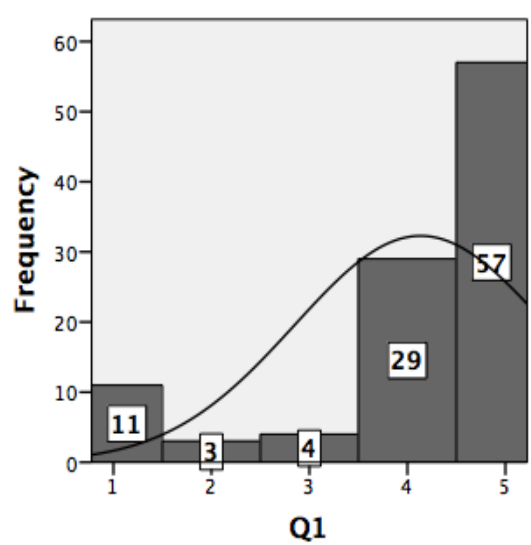

Figure12

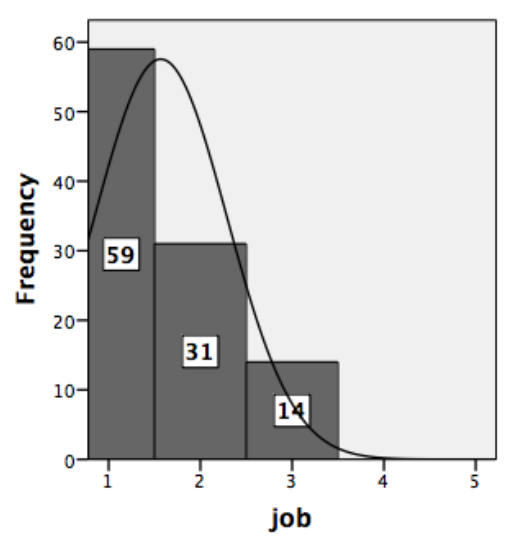

Figure14

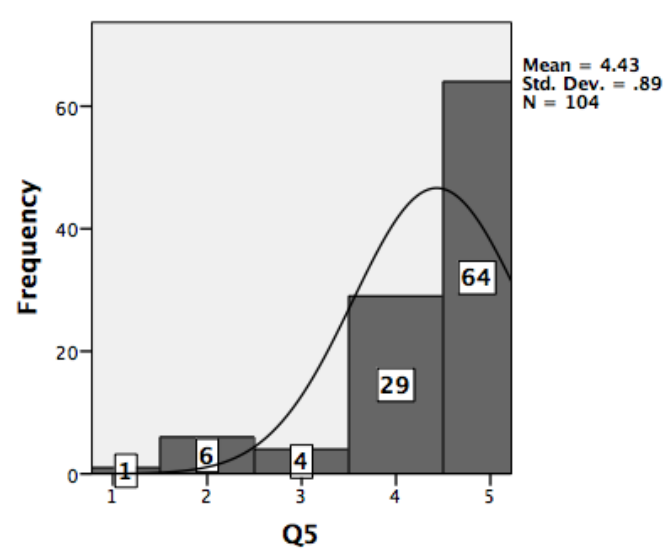

Figure16

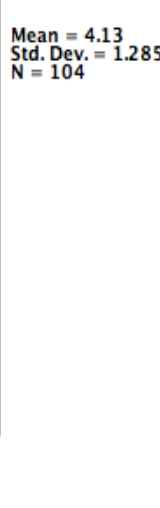

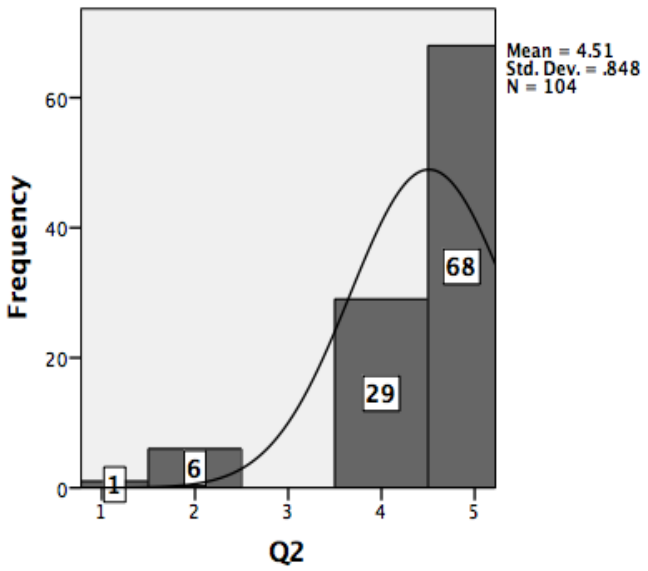

Figure11

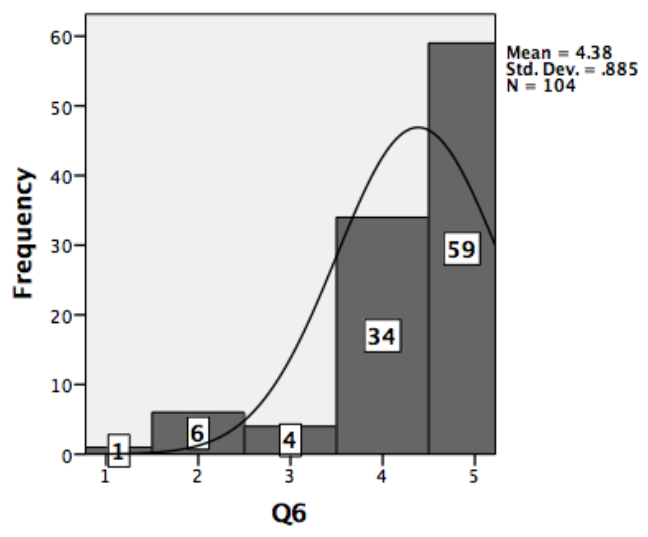

Figure13

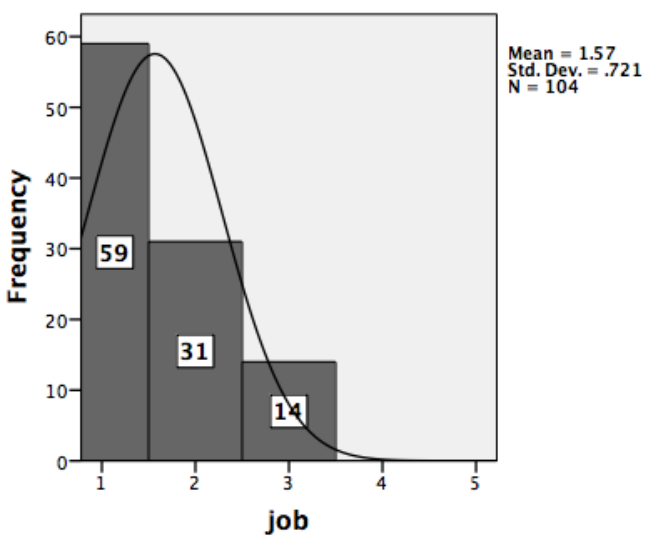

Figure15

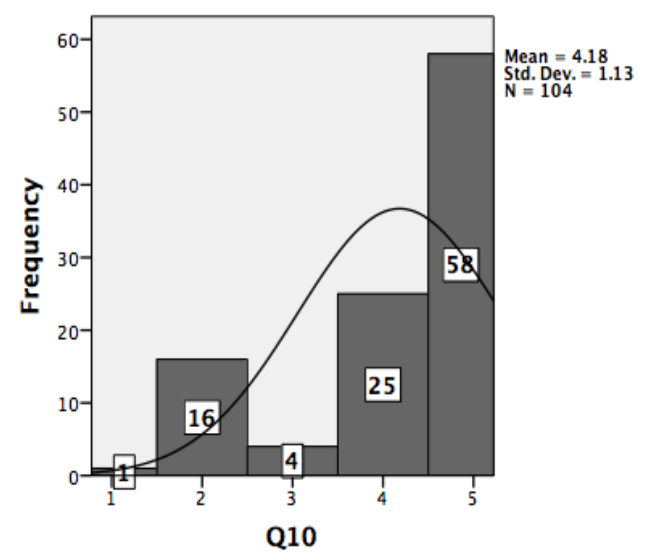

Figure17 


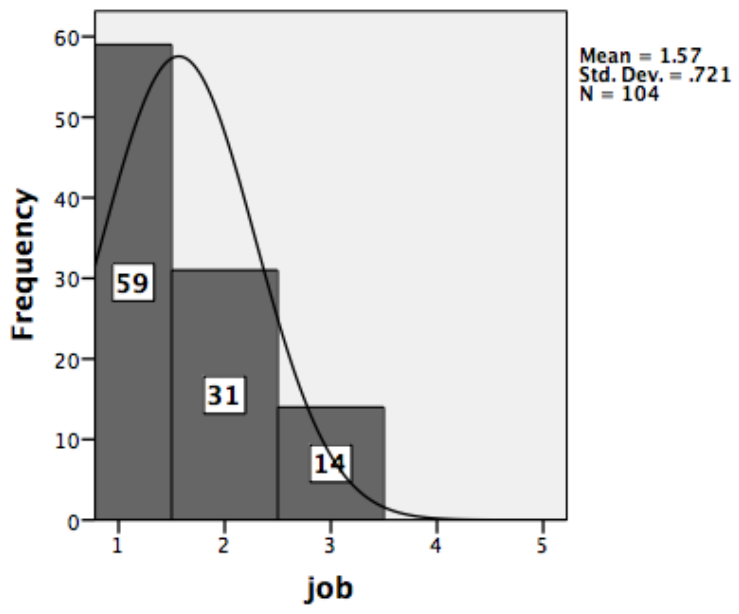

Figure18

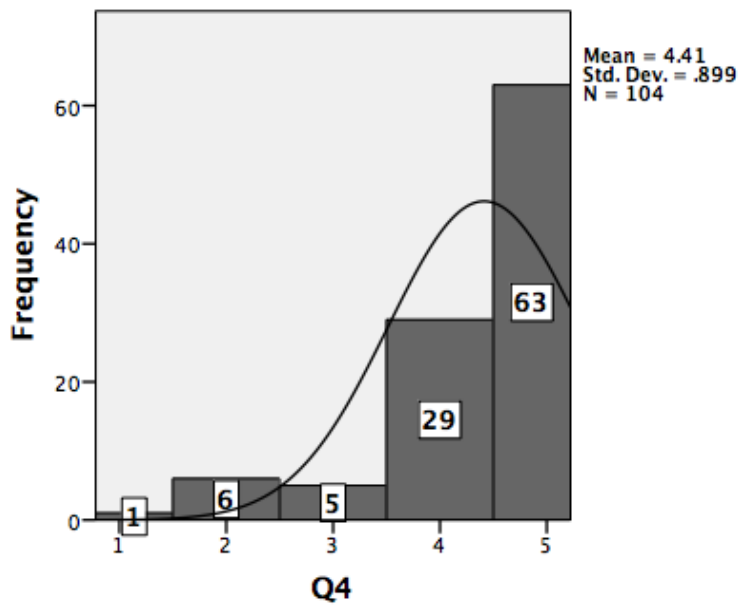

Figure19

\section{Conclusion}

From the above analysis the following percentage of the respondents who has answered the following questionnaire questions by agree and strongly. Where these questions have a high impact on the projects delay

1. Q2: Do the projects bids cause the delay? $=93.3 \%$

2. Q7: Is due to the lack of coordination at work between the parties? $=90.4 \%$

3. Q3: Are due to delayed payment to contractors? $=90.3$

4. Q5: Is it due to decisions hesitation and contradictory? $=89.4 \%$

5. Q6: Is due to the lack of experience of the project manager and the Cite engineer and? $=89.4 \%$

6. Q4: Is it due to the change in essential engineering design? $=88.5 \%$

7. Q8: is due to the lack of top management coordination with work parties? $=87.5 \%$

8. Q14: Is due to the pressure of higher authorities to complete the projects so quickly?=87.5\%

9. Q9: is due to the lack of experience of the Project Manager and site engineers? $=86.6 \%$

10. Q13: Is due to the lack of the using new technology? $=84.6 \%$

11. Q1: Are there delay projects? $=82.7 \%$

12. Q12: Is due to the lack of follow-up to the decisions of the senior management? $=81.8 \%$

13. Q10: Is due to administration complexities and administration routines? $=79.8 \%$

14. Q11: Is due to the administration decentralization? $=78.9 \%$

\section{REFERENCES}

Aedwin Regi Varghese1, Shibi Varghes (November-December, 2015). Analysis Of Delays In Construction Projects. International Journal of Engineering Research and General , 3 (6)

Ayudhya B. I, (Nov. 2011). Evaluation of Common Delay Causes of ConstructionProjects in Singapore. Journal of Civil Engineering and Architecture

Frank D.K., Adwoa B. and Agyakwah-Baah, (2010). Delays in Building Construction Purojects in Ghana. Australasian Journalof Construction Economics and Building

Gidado Kassim and Niazai Ghulam, (10-11th September, 2012. ). Causes of Project Delay in the Construction Industry in Afghanistan. http://eprints.brighton.ac.uk/id/eprint/11129 University of Brighton, $U K$

Haseeb J, 2011, Problems Of Projects And Effects Of Delays In The Construction Industry Of Pakistan. Australian Journal of Business and Management Research

Menesi R., (2007). Construction delay analysis undermultiple baseline updates. A Thesis Report 
Omayma Hashim Motaleb1 and Mohammed Kishk2. (2015). Controlling the Risk of Construction Delay in the Middle:State-of-the-Art Review. Journal of Civil Engineering and Architecture

Prakash Rao, B. and Joseph Camron Culas. (June, 2014). Review Articlecauses Of Delays In Construction Projects- A Case Study. Internationaljournalof Current Research, 6 (06)

Seboru, M. A. (April 8, 2015). An Investigation into Factors Causing Delays in RoadConstruction Projects in Kenya. American Journal of Civil Engineering

Towhid Pourrostam and Amiruddin Ismail. (5, October 2012). Causes and Effects of Delay in Iranian Construction Projects. IACSIT International Journal of Engineering and Technology

Willum, M. (2007). Construction delay analysis under multiple baseline updates. A Thesis Rep 